Section Editor Mitchell S.V. Elkind, MD, MS

Daniel Tibussek, MD Michael Karenfort, MD

Ertan Mayatepek, MD Birgit Assmann, MD

Address correspondence and reprint requests to Dr. Daniel Tibussek, Department of General Pediatrics, Division of Paediatric Neurology,

University Children's Hospital, Heinrich-Heine-University Düsseldorf, Moorenstr. 5, D40225 Düsseldorf, Germany daniel.tibussek@med.uniduesseldorf.de

\section{Clinical Reasoning: Shuddering attacks in infancy}

回的

\section{SECTION 1}

A 6-month-old boy was brought in by his parents because of a series of paroxysmal shivering episodes. The parents were able to document one attack on video (video 1 on the Neurology ${ }^{\circledR}$ Web site at www.neurology.org). The attack began with sudden staring, followed by opening of the mouth, noisy stridulous inspiration, and shivering movements predominantly of his neck and shoulders. This was accompanied by a slight deviation of his eyes, head, and mouth to the right side. The parents reported that these attacks seemed to occur particularly while eating (video 2) and were often preceded by myoclonic jerks of the mouth. The patient was staring but seemed alert. Onset and termination of the events were always abrupt and the child immediately continued his activities. Duration of the episodes was no longer than 5 to 15 seconds.

We were able to observe more than 20 of these episodes within a period of 48 hours while he was hospitalized (example given in video 3 ).

\section{Questions for consideration:}

1. How would you describe these movements?

2. What is your differential diagnosis at this point?

3. What further testing would you recommend? 


\section{SECTION 2}

The attacks were initially believed to be focal seizures because the shivering movements were repeatedly preceded by right perioral myoclonic jerks. Repeated video-EEG recordings was performed, but did not reveal any changes in the EEG other than muscle artifacts.

On the basis of published descriptions of similar fits in infancy, ${ }^{1}$ the diagnosis of shuddering attacks was suspected. No further diagnostic workup was undertaken.

On follow-up the frequency of the attacks gradually decreased, and they eventually seemed to have ceased after 3 months. However, at the age of 15 months the episodes resumed, and another home video was sent to us. At this time the attacks were provoked by an attempt to stick a fork into a piece of bread (video 4). In addition, the mother had observed shuddering attacks provoked by pressing Lego bricks together. This relapse lasted for less than 1 week and was followed by another uneventful period of 6 months. Again, after that time the parents observed sporadic shuddering attacks (not more than one a day) which were somewhat milder than at original presentation.

At the age of 24 months the parents provided another video documenting a third relapse (video $5)$. While playing with his mother the child is pretending to wash his hair and in the end is asked to shake his head in order to "dry his hair." However, in attempting to shake his head he provokes another shuddering attack. Again and again the mother could reproduce this phenomenon. At the last follow-up, aged 26 months, the parents reported shuddering attacks frequently occurring just after coming out of the bath.

\section{Questions for consideration:}

1. What other information would you request at this time?

2. How would you advise the parents? 


\section{SECTION 3}

Regular neurologic examinations during the first 2 years of life have not revealed any additional abnormalities. In addition, at the age of 2 years the child was scored as being within normal limits on the Mental Scale and the Motor Scale of the Bayley Scales of Infant Development, Second Edition (BSID-II), a widely used measure of cognitive and motor development in infancy. ${ }^{2}$ The BSID-II comprises three separate scales (the Mental Scale, the Motor Scale, and the Behavior Rating Scale). Performance is measured through Mental Development Index (MDI) and Psychomotor Development Index (PDI) scores. Index scores have a mean of 100 ( \pm 15$)$. Scores between 85 and 114 are classified as within normal limits.

No family history of essential tremor was reported.

DISCUSSION Shuddering attacks are benign nonepileptic events that typically begin in infancy. The clinical events consist of rapid shivering of the head, shoulder, and occasionally the trunk. As in our patient, events have been reported as brief, usually lasting not more than a few seconds. Frequency can be up to more than 100 events per day with a great inter- and intraindividual variability. ${ }^{3,4}$ In our patient, attacks seemed to be precipitated not only by feeding or eating, which has been interpreted as stimulus overflow by some authors, ${ }^{3}$ but also by head movements and certain tasks (pressing toys together or sticking a fork into a piece of bread).

Shuddering attacks are not epileptic in nature. Ictal EEG is normal in this syndrome, and typically no neurologic abnormalities are found. However, confusion with tonic, myoclonic, and absence seizures, and with West syndrome, has been reported. This misdiagnosis may lead to unnecessary anticonvulsive treatment. ${ }^{5}$ Therefore, EEG is advocated in all patients and ictal video documentation should always be attempted by caregivers. In cases with unusual clinical presentations, prolonged video EEG monitoring is helpful. Other events which can mimic myoclonic seizures in the infant may also be taken into consideration, mainly benign myoclonus of early infancy or gratification disorder.

The pathophysiology of shuddering attacks is unknown, although a relationship to essential tremor has been postulated. ${ }^{6,7}$ This was initially based on the observation of six infants and young children presenting with a history of shuddering attacks who exhibited postural tremor on examination and who had a positive family history of tremor. ${ }^{6}$ Successful treatment of shuddering attacks with propanolol, a first line agent in the treatment of essential tremor, was reported years later. ${ }^{7}$ Moreover, the EMG pattern during the attacks has been reported to be very similar to that of essential tremor. ${ }^{8}$ However, a recent study on essential tremor in 39 patients $<18$ years did not find any patient with a history of shuddering attacks during infancy or among family members. ${ }^{9}$ Accordingly, in more recent cases reports ${ }^{8,10}$ no positive family history for essential tremor was reported.

Although the incidence of shuddering attacks has been reported to be low, our personal experience leads us to conclude that the incidence may be underestimated. Since this case presented to our hospital, we were able to diagnose three additional cases within 12 months. In support of this view, a retrospective study of paroxysmal nonepileptic events in 666 pediatric patients found $7 \%$ of all events to be shuddering attacks. ${ }^{11}$

Further investigations in affected infants are usually not indicated. Reassurance of parents is crucial since relatives are often frightened by the unexpected appearance and often high frequency of the attacks. Spontaneous remission can be expected according to previous reports. ${ }^{3}$

However, if progression occurs or additional neurologic abnormalities are found on examination, further diagnostic evaluation including cerebral imaging is indicated, as there have been reports of symptomatic shuddering attacks. ${ }^{8}$

\section{ACKNOWLEDGMENT}

The authors thank the parents for their consent to publish these videos. They also thank Prof. Stephenson, Glasgow, and his panel of "fits and faints" experts for discussion of the videos.

\section{REFERENCES}

1. Rothner AD. "Not everything that shakes is epilepsy." The differential diagnosis of paroxysmal nonepileptiform disorders. Cleve Clin J Med 1989;56 (suppl pt 2): S206-S213.

2. Bayley N. Bayley Scales of Infant Development. 2nd ed. San Antonio, TX: The Psychological Corporation, 1993.

3. Laux L, Nordli DR. Nonepileptic spells in neonates and infants. In: Kaplan WK, Fisher RS, eds. Imitators of Epilepsy, 2nd edition. New York: Demos; 2005:8384.

4. Holmes G, Russman B. Shuddering attacks: evaluation using electroencephalographic frequency modulation radiotelemetry and videotape monitoring. Am J Dis Child 1986;140:72-73.

5. Metrick ME, Ritter FJ, Gates JR, Jacobs MP, Slcare SS, Loewenson RB. Non epileptic events in childhood. Epilepsia 1991;32:322-328. 
6. Vanasse M, Bedard P, Andermann F. Shuddering attacks in children: an early clinical manifestation of essential tremor. Neurology 1976;26:1027-1030.

7. Barron TF, Younkin DP. Propranolol therapy for shuddering attacks. Neurology 1992;42:258-259.

8. Kanazawa O. Shuddering attacks-Report of four children. Pediatr Neurol 2000;23:421-424.

9. Jankovic J, Madisetty J, Vuong KD. Essential tremor among children. Pediatrics 2004;114:1203-1205.

10. Palencia R. Crisis de estremecimiento (Shuddering attacks). Un raro trastorno paroxístico motor no epiléptico en la primera infanzia. Bol Pediatr 2001;41:33-35.

11. Bye AM, Kok DJ, Ferenschild FT, Vles JS. Paroxysmal non-epileptic events in children: a retrospective study over a period of 10 years. J Paediatr Child Health 2000; 36:244-248. 


\title{
Neurology
}

\author{
Clinical Reasoning: Shuddering attacks in infancy \\ Daniel Tibussek, Michael Karenfort, Ertan Mayatepek, et al. \\ Neurology 2008;70; e38-e41 \\ DOI 10.1212/01.wnl.0000306698.75592.6e
}

This information is current as of May 16, 2008

\author{
Updated Information \& \\ Services \\ Supplementary Material \\ References \\ Permissions \& Licensing \\ Reprints
}

including high resolution figures, can be found at: http://n.neurology.org/content/70/13/e38.full

Supplementary material can be found at: http://n.neurology.org/content/suppl/2008/08/28/70.13.e38.DC1

This article cites 9 articles, 2 of which you can access for free at: http://n.neurology.org/content/70/13/e38.full\#ref-list-1

Information about reproducing this article in parts (figures,tables) or in its entirety can be found online at:

http://www.neurology.org/about/about_the_journal\#permissions

Information about ordering reprints can be found online:

http://n.neurology.org/subscribers/advertise

Neurology ${ }^{\circledR}$ is the official journal of the American Academy of Neurology. Published continuously since 1951, it is now a weekly with 48 issues per year. Copyright . All rights reserved. Print ISSN: 0028-3878. Online ISSN: 1526-632X.

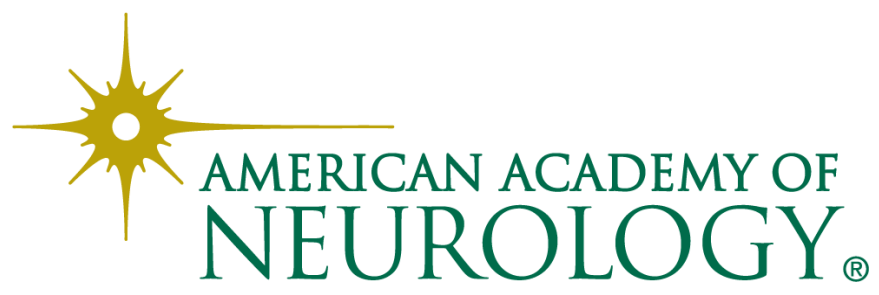

